\title{
Citrus aurantifolia (Lime) juice extract reverses poly cystic ovary in Cadmium chloride exposed sprague dawley rats
}

\author{
Yibala Oboma $^{1 *}$, Beredugo Sylvanus ${ }^{1}$, Archibong Anietie $M^{2}$ and Zipamone Emmanuella ${ }^{1}$ \\ ${ }^{1}$ Department of Medical Laboratory science, Faculty of Basic Medical Sciences, College of Health Sciences, Niger Delta University Wilberforce Island Bayelsa State, Nigeria \\ ${ }^{2}$ Department of Histopathology, University of Uyo Teaching Hospital Uyo Akwa Ibom State, Nigeria
}

\begin{abstract}
Cadmium $(\mathrm{Cd})$ is a unique metal among the heavy metals due to its diverse toxic effects, extremely protracted biological half-life, low rate of excretion from the body, and predominant storage in soft tissues. The study was aimed at evaluating the curative potentials of Citrus aurantifolia (Lime) juice extract on cadmium chloride induced ovary tissue toxicity. Female Sprague Dawley adults were grouped into six ( $\mathrm{n}=5$ ), Group A-Group F. All the groups were subjected to 48 hours fasting. Group B, group C, group D and group F were induced with double dose of $0.5 \mathrm{mg} / \mathrm{kg}$ body weight of $\mathrm{Cadmium}$ chloride $\left(\mathrm{CdCl}_{2}\right)$ orally using oral gastric tube. Group A and group E were exposed to $0.5 \mathrm{ml} / \mathrm{kg}$ of physiological saline. The rats were allowed access to food and water post 24 hours of drug administration. Group B, C, D and group E were further subjected to treatment with lime juice twice daily for 6 weeks post 72 hours of exposure to cadmium chloride while Group F was left untreated. Group B was treated with $1 \mathrm{ml} / 100 \mathrm{~kg}$ weight of fresh Citrus aurantifolia (Lime) juice ; group C received $1.5 \mathrm{ml} / 100 \mathrm{~kg}$ of fresh lime juice while group $\mathrm{D}$ and Group $\mathrm{E}$ received $2 \mathrm{ml} / 100 \mathrm{~kg}$ of fresh lime juice respectively twice a day for six weeks. Photomicrograph shows abnormal ovary epithelium with spindle to round cells scattered in a collagenous background and failure of oocyte development. Cadmium chloride induces surface epithelium disorder and failure of oocyte development as well as cystic follicles while treatment with the Citrus aurantifolia (Lime) juice reverses the disorder in a dose dependent pattern.
\end{abstract}

\section{Introduction}

Cadmium (Cd) is a unique metal among the heavy metals reported globally [1]. This is due to its diverse toxic effects, extremely protracted biological half-life, low rate of excretion from the body, and predominant storage in soft tissues primarily the liver, kidney and reproductive organs in humans[2].The deteriorating effects of cadmium on the ovaries, testis, kidney, liver has been reported among people living in cadmium chloride polluted areas [3,4]. Previous studies on rodents has shown that cadmium alters the levels of testosterone, Luteinizing hormone (LH), Follicle stimulating hormone (FSH), essential for proper functioning of the female reproductive system. It is reported to mimics the growth-promoting actions of estrogen responsible for mammary gland development, induces early puberty in females, and also increases overall lifetime breast cancer risk in females [5]. Histomorphology studies in rabbits had shown that cadmium causes degeneration of oocyte follicles and multi oocyte follicles with significant increase in number of atretic follicles [2,3]. Citrus aurantifolia (lime) is used locally in many countries for management of different medical conditions [6]. Citrus aurantifolia (lime) juice contains potential antioxidants; these antioxidants have been demonstrated to prevent metal-induced toxicities [7]. Gharagozloo and Ghaderi, [8] also reported that Citurs aurantifolia (Lime) can protect against proliferation of cancer cells in human body and tissue culture. Also, products of citrus fruit such as essential oil and pectin are used in the cosmetic and pharmaceutical industries for the management of certain disorders [9]. Citrus aurantifolia in its natural state is widely used in West Africa, particularly in Nigeria where it is employed and use in the treatment /management of several illnesses in humans. It is a major component of most herbal preparations in Nigeria [10]. The leaves stem and bark has been reported to cure some illnesses such as fever, stomach ulcer and conjunctivitis. In South West Nigeria, the roots, bark, stem twigs, leaves and fruits are used in the treatment of malaria [6] and the diluted forms of the fruit juice is used for mouth washing for the treatment of mouth and throat ulcers in humans [11]. It is proven to have significant antimycobacterial activity especially against the isoniazid-resistant strain of Mycobacterium tuberculosis.

Citrus aurantifolia juice possesses immune modulatory potentials in mitogen activated cultured mononuclear cells. The result from previous studies revealed that the juice significantly inhibits the proliferation of phytohaemaglutinin activated mononuclear cells at 250 and 500 microgram per litre of the juice extract. It is used as an astringent and toning action to clear oily skin acne and treat cuts [12]. Nallely, et al. [13] study revealed that the extracts of root of $C$. aurantifolia possess antibactericidal activity against a wide range of microorganism such as Staphylococcus aureus, Klebsiella pneumoniae, Proteus mirabilis, Pseudomonas aeruginosa, ßeta-haemolytic streptococci, Escherichia coli and Neisseria gonorrhoeae affecting humans. Citrus aurantifolia equally protect against, breast cancer, neuroblastoma, pancreas cancer and prostate cancer cells. D-limonene, D-dihydrocarvone, limoniods and flavonoids are among the major phytoconstituent in C. aurantifolia responsible for the anticancer activity. The essential oil of C. aurantifolia has 78\% inhibition of human colon cancer cells, DNA fragmentation and apoptosis induction as revealed from a study and it is suggestive of the potential use of the plant for prevention of cancer especially colon cancer [14]. Furthermore, studies on the $C$.

${ }^{\star}$ Correspondence to: Yibala Oboma, Department of Medical Laboratory Science, FBMS, CHS, Niger Delta University Wilberforce Island Bayelsa State, Nigeria, E-mail: yoboma78gmail.com

Key words: lime juice, ovary, epithelium, cadmium

Received: April 04, 2020; Accepted: May 07, 2020; Published: May 11, 2020 
aurantifolia juice and fruit peels as well as leaves of C. aurantifolia has shown that the plant has a concentration-dependent effect on low density lipoprotein (LDL). C. aurantifolia acts as antioxidant both in vitro and in vivo and the vitamin $\mathrm{C}$ component protects plasma lipids and LDL against peroxidative/free radicals' damage induced by various types of oxidation processes in the human body [6]. In addition, vitamin $\mathrm{C}$, one of the components of citrus juice and peels have shown to play an important role in enhancing immune system, fighting against the formation of free radicals that cause muscle damage. Pourhossein, et al. [15] reported that dietary supplementation of citrus peels extract caused the improvement of immune response and disease resistance in broiler. Also study by Asnaashari, et al. [16] on the effect of essential oil of C. aurantifolia on weight gain in mice showed that mice treated with the extract displayed a reduction in both the amount of food intake and body weight compared with the control group with increase in body weight. Another interesting finding was that co-administration of $C$. aurantifolia essential oil and ketotifen causes a decreased weight gain in mice due to its anorexia property.

Citrus aurantifolia juice have shown ability to reduce the number of ova shed in Sprague-Dawley rats and also caused irregularities of the estrous cycle, partially block ovulation and also caused irregularities in the histology of the ovaries and uterus and possibly compromise fertility in females. More so, C. aurantifolia juice showed abortificient effect, although it does not possess teratogenic effect on foetus in some studies. In Nigeria, a survey conducted by Imade, et al. [17] in Jos revealed that it is a common practice for women to use C. aurantifolia juice solutions as a post coital douche with the believe that it prevents pregnancy or sexually transmitted diseases such as HIV and as well as enhancer sexual pleasure. Similarly, the hydro alcohol extract of C. aurantifolia in the form of tincture has been found to have antiplatelet aggregation activity. It was found to have significant inhibitory effects on ADP and epinephrine-induced platelet aggregation [6]. In an interesting human clinical trial, orange juice was shown to elevate HDL cholesterol ("good" cholesterol) while lowering LDL (so-called bad) cholesterol [18]. The efficacy of C. aurantifolia and C. sinensis against osteoporosis was evaluated in an ovariectomized rat model, and the result revealed that the administration of citrus extracts increases the trabecular bone mineral content, and mineral density of tibia and improved the levels of phosphorus and calcium. The research demonstrates that $C$. aurantifolia possesses the ability to reduce bone loss [6]. In humans, chronic exposure to environmentally related
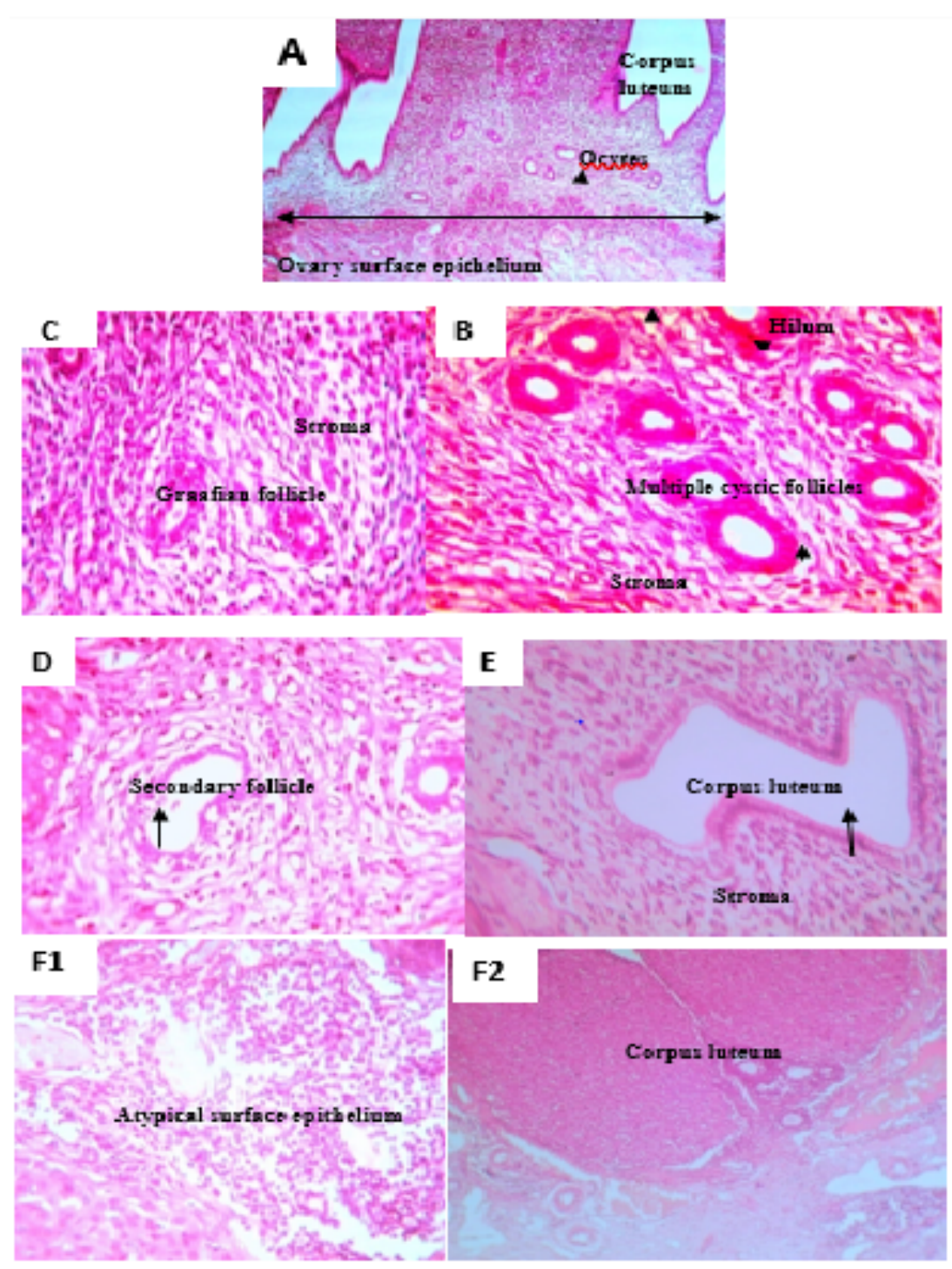

Figure 1. Photomicrograph of Ovarian tissue stained with heamatoxylin and eosin X 400 magnification 
cadmium results in high cadmium level, especially in infertile males and females. Therefore, this study was aim at evaluating the curative ability of lime juice extract on cadmium induced ovary tissue toxicity.

\section{Materials and method}

Thirty female Sprague Dawley adult rats with body weight ranging from $150 \mathrm{~g}-250 \mathrm{~g}$ were purchased from the animal breeding and research unit of the Department of Pharmacology and Toxicology, Faculty of Pharmacy, Niger Delta University Wilberforce Island, Bayelsa state. The adult rats were kept in six (6) cages labeled accurately in a ventilated room with normal room temperature for the period of 2weeks acclimatization. They were fed with mash hybrid feeds (Vital feeds Ltd. Edo State) and water (ad libitum). All animals were handled in accordance with the EU directive for animals (2010/63/EU).The Sprague Dawley female adult rats were grouped in to six (6) where $n=5$, All the groups (rats) were subjected to 48hours fasting and thereafter a double dose of $0.5 \mathrm{mg} / \mathrm{kg}$ body weight of Cadmium chloride $\mathrm{CdCl}_{2}$ was administered orally using oral gastric tube to rats in groups $\mathrm{B}, \mathrm{C}$, $\mathrm{D}$, and $\mathrm{F}$ twice a day. Group A and group E were exposed to $0.5 \mathrm{ml} / \mathrm{kg}$ of physiological saline. The rats were all allowed accessed to food and water post 24 hours of drug administration. Groups B, C, D and group E were subjected to treatment with $C$. aurantifolia (lime) juice twice daily for 6 weeks post 72 hours of exposure while Group F was left untreated. Group B was treated with $1 \mathrm{ml} / 100 \mathrm{~kg}$ weight of fresh lime juice; group C received $1.5 \mathrm{ml} / 100 \mathrm{~kg}$ of fresh lime juice while group D and Group E received $2 \mathrm{ml} / 100 \mathrm{~kg}$ of fresh lime juice respectively once a day for six weeks.

\section{Sample collection and preparation}

The adult female rats were sacrificed under anesthesia using chloroform. The ovary tissues were harvested and fixed immediately in $10 \%$ buffered formal saline and further stained for microscopy. The tissues were processed using automatic tissue processor and tissues sectioned using rotary microtome into serial sections and were stained. Erhlich's haematoxylin and Eosin method was used for histomorphology assessment in accordance with the method of Nwidu and Oboma [19]. The slides were stained and read to establish diagnosis as shown in the photomicrographs. The principle of reaction is based on the chemical theory of dye; where the acidic component of the tissue was stained by the basic dye (haematoxylin) blue and the basic component (cytoplasm) is stained by the acidic dyes (Eosin).The slides were dewaxed and hydrated in water, drained and transferred to haematoxylin solution (primary stain) for $20 \mathrm{~min}$. with nuclei staining blue. Rinsed in water and immediately subjected to two seconds differentiation using 1\% acid alcohol, rinsed to stop reaction and blued in Scot's tap water to restore the nuclear stain. Then dehydrated in three changes of alcohol (70\%, 95\%, Absolute) and counterstained with $1 \%$ Eosin (cytoplasm stain). The stained slides were dehydrated in two changes of alcohol (95\% and Absolute) and cleared in xylene and mounted with DPX.

\section{Results}

Photomicrographs of the stained tissue sections were produced using a digital microscope (Olympus ${ }^{\circ}$ ) at $\times 400$ magnification. Heamatoxylin and eosin is a routine and gold standard stains used in histopathology to study general tissue structures. In the photomicrographs shown below, heamatin an oxidative product of haematoxylin stained the nuclei of the oocyte blue and eosin stained the cytoplasm pink. Group A (negative control) shows a photomicrograph of a normal ovary displaying ovary surface epithelium (a modified mesothelial epithelium compose of a single layer columnar to cuboidal epithelium), hilum and oocyte consistent with normal histology of the ovary. Group B photomicrograph shows an ovary tissue of an adult rat exposed to 0.5 $\mathrm{mg} / \mathrm{kg}$ body weight cadmium chloride twice daily and pretreated with $1 \mathrm{ml} / \mathrm{kg}$ body of lime twice daily. The histomorphology shows graffian follicle and abundant stroma consistent with normal histology of the ovary. Group C shows a photomicrograph of an ovary section of an adult rat exposed to $0.5 \mathrm{mg} / \mathrm{kg}$ body of cadmium chloride twice daily and treated with $1.5 \mathrm{ml} / \mathrm{kg}$ body weight of lime showing multiple cystic follicles, indicating non proliferating epithelium. Group D shows ovary sections of an adult exposed to $0.5 \mathrm{~g} / \mathrm{kg}$ body of cadmium chloride twice daily and treated with $2 \mathrm{ml} / \mathrm{kg}$ of fresh lime juice showing secondary follicle and abundant stroma consistent with normal histology while Group E (negative drug control) not exposed but pretreated with $2 \mathrm{ml} /$ $\mathrm{kg}$ body of lime twice daily shows normal corpus luteum cyst. Group F (drug control) shows ovarian tissue of an adult rat exposed to 0.5 $\mathrm{mg} / \mathrm{kg}$ body weight cadmium chloride twice daily without treatment. Photomicrograph (group F) shows abnormal ovary epithelium with spindle to round cells scattered in a collagenous background and failure of oocyte development. Cadmium chloride induces ovary surface epithelium disorder and failure of oocyte development as well as cystic follicles. The lime juice demonstrated a dose dependent protective property to cadmium chloride $\mathrm{CdCl}_{2}$ induced lesion.

\section{Discussion and conclusion}

Cadmium (Cd) is an environmental contaminant. It is unique among metals because of its diverse toxic effects, extremely protracted biological half-life, low rate of excretion from the body, and predominant storage in soft tissues primarily the liver, kidney and reproductive organs [2]. According to $\mathrm{Wu}$, et al. [3] Cadmium is capable of penetrating through tissues rapidly and most of the ingested cadmium enters into the liver and the kidneys and the female reproductive system. The current study revealed that Cadmium chloride is toxic to the ovary. Cadmium chloride $\mathrm{CdCl}_{2}$ induces surface epithelium disorder, failure of oocyte development and multiple cystic follicle in the present study. Lafuente, [5] in his study using rodents documented that cadmium alters the level of testosterone, LH, Follicle stimulating hormone (FSH), essential for reproduction. Cadmium can also mimics the growth-promoting actions of estrogens, promoting mammary gland development, inducing early puberty in females, and increasing overall lifetime breast cancer risk. Also, Massani, et al. [2] study in rabbit showed that cadmium causes a degeneration of oocyte follicles and multi oocyte follicles as seen in the present study.

Exposure to cadmium is reported by previous studies to be linked to several detrimental effects on both male and female reproductive system, also acknowledged endocrine disrupting chemicals (EDCs) [20]. Though, specific ovary pathology was not explored in previous studies as it is on the current work. The role of Citurs aurantifolia (Lime) on cadmium chloride induced ovarian pathology was evaluated in the present study and a dose dependent protective effect was reported. High concentration of lime juice prevented multiple cystic development and reverses abnormal epithelial cells of the ovary caused by cadmium chloride as observed in Group treated with $2 \mathrm{ml} /$ $\mathrm{kg}$ body weight with fresh lime juice. This effect is in agreement with Gharagozloo and Ghaderi, [8] who have also reported that Citurs aurantifolia (Lime) protect against proliferation of cancer. Low doses cause non proliferating activities of the developing follicles and are in accordance with Bakare, et al. [21,22] who has reported abortifacient effect. The present ameliorating effect of lime juice on Cadmium chloride induced lesions recorded in this study is in agreement with Ayinde, et al. [7] who reported that Citrus is used locally in many countries for management of different medical conditions and that the Citrus aurantifolia juice contains potential antioxidant and such 
antioxidants have been demonstrated to prevent metal-induced toxicities. Medicinal plants in Nigeria forest if properly harnessed may provide an alternative measure for the management of certain diseases. In conclusion Cadmium chloride induces ovary surface epithelial disorder and prevented the growth of developing follicles. Citrus aurantifolia juice extract reverses this conditions in a concentration gradient dependent pattern.

\section{References}

1. Nordberg GF (2009) Historical perspective on cadmium toxicology. Toxicol Appl Pharmacol 238: 192-200.

2. Massanyi P, Uhrin A, Sirotkin V, Pasky K, Forgacs Z, et al. (2000) Effects of cadmium on ultrastructure and steriodogenesis in cultured porcine ovarian granulose cells. Acta vet Brno 69: 101-106.

3. Wu SY, Tian J, Wang MZ, Pan BJ, Lu HD, et al. (2004) The effect of cadmium pollution on reproductive health in females. Zhonghua Liu Bing Xue Za Zhi 25: 852-855.

4. Piasek M (2001) Placental cadmium and progesterone concentrations in cigarette smokers. Reprod Toxicol 15: 673-681.

5. Lafuente A (2004) Cadmium exposure differentially modifies the circadian patterns of norepinephrines at the median eminence and plasma LH, FSH and testosterone levels. Toxicol Lett 146: 175-182.

6. Onyilofe SE, Ibukun OO, Madu S, Bala I, Sotonye O, et al. (2015) Ethanomedical importance of Citrus aurantifolia (christm) Swingle. J Pharm Innov 4: 01-06.

7. Aibinu I, Adenipekun T, Adelowotan T, Ogunsanya T, Odugbemi T (2007) Evaluation of the antimicrobial properties of different parts of Citrus aurantifolia (lime fruits) as used locally. Afr J Tradit Complement Altern Med 4: 185-190.

8. Gharagozloo M, Ghaderi A (2001) Immunomodulary effect of concentrated lime juice extract on activated human mononuclear cells. J Ethnopharmacol 77: 85-90.

9. Aprioku JS, Briggs OE (2018) Citrus aurantifolia (lime) juice negatively influences Estrous cycle of Wistar Rats. IORS J Pharm 8: 4338-4339.

10. Ayinde O, Ogunnowo C, Ogedegbe RA (2012) Influence of vitamin C and Vitamin E on testicular zinc content and testicular toxicity in lead exposed Albino rats. $B M C$ Pharmacol Toxicol 13: 13-17.
11. Aibunu I, Adenipekun T, Adelowotan T, Ogunsanya T, Odugbemi T (2007) Evaluation of the antimicrobial properties of different parts of Citrus aurantifolia (lime fruit) as used locally. Afr J Tradit Complement Altern Med 4: 185-190.

12. Akhtar SS (2013) Evaluation of cardiovascular effects of Citrus aurantifolia fruits Soc Sci Res 2013.

13. Kunow MA (2003) Maya Medicine: Traditional Healing in Yucatan. UNM Press, New Mexico, 117.

14. Nalley E, Sandoval M, Abraham G, Elizondo-Trevino E, Garza-Gonzalex E, et al (2012) Chemical composition of Hexane extracts of Citrus aurantifolia and antimycobacterium tuberculosis activity of its constituents. Molecules 17: 11173-11184.

15. Jayaprakasha GK, Mandadi KK, Poulose SM, Jadegoud Y, Patil BS (2008) Novel triterpeniod from Citrus aurantifolia L. possess chemopreventive properties against human colon cancer cells. Bioorg Med Chem 16: 5939-5951.

16. Pourhossein Z, Qotbi AA, Seidavi A, Laudadio V, Centoducati G, et al. (2014) Effect of different levels of dietary sweet orange (Citrus sinensis) peel extract on humoral immune system responses in broiler chickens. Anim Sci J 4: 4-7.

17. Asnaashari S, Delazar A, Habibi B, Vasfi R, Nahar L, et al. (2014) Essential oil from Citrus aurantifolia (lime fruits) prevents ketotifen induced weight gain in mice. Phytotherapeutic Resource 24: 1893-1897.

18. Imade GE, Sagay AS, Onwuliri VA, Egah DZ, Potts M (2005) Use of lemon or lime juice douches in women in Jos, Nigeria. Sex Health 2: 237-279.

19. Jyotsna A, Saonere S (2011) An overview of Citrus aurantifolia in treatment of various diseases. Afr J Plant Sci 5: 390-395.

20. Legbosi NL, Oboma YI (2019) Nauclea latifolia stem $\square$ bark extract protects the prefrontal cortex from valproic acid $\square$ induced oxidative stress in rats: Effect on B cell lymphoma and neuron specific enolase protein expression. GSC Biol Pharm Sci 7: 044 .

21. Souza A, Lamidi M, Ibrahim BR, Aworet RR, Samseny M, et al. (2011) Antihypertensive effect of an aqueous extract of Citrus aurantifolia (Rutaceae) (christm) swingle, on arterial blood pressure of mammals. Int Res J Pharm 1: 142-148.

22. Bakare AA, Bassey RB, Okoko IE, Sanyaolu AO, Asharnu AE, et al. (2012) Effect of lime juice of Citrus aurantifolia on histomorphological alterations of the ovaries and uterus of cyclic Sprague-Dawley Rats. Eur J Sci Res 67: 607-616.

Copyright: $\odot 2020$ Oboma Y. This is an open-access article distributed under the terms of the Creative Commons Attribution License, which permits unrestricted use, distribution, and reproduction in any medium, provided the original author and source are credited. 